\title{
Non descent vaginal pan hysterectomy in benign ovarian tumour in elderly parous patients - an experience
}

\author{
Arun Paul Choudhury, Pranoy Nath \\ Correspondence: Dr Pranoy Nath, Associate Professor, Department of Obstetrics and \\ Gynaecology, Silchar Medical College, Silchar, Assam; Email - drnathdas@gmail.com \\ Distributed under Creative Commons Attribution-Share Alike 4.0 International.
}

\begin{abstract}
Objectives: 1) To study the feasibility of performing and outcome of vaginal hysterectomy in uteri without any descent and associated with benign ovarian tumour. 2) To compare the outcome of vaginal hysterectomy over hysterectomy performed through abdominal route and laparoscopically. Methodology: Three hundred (300) patients requiring pan hysterectomy for benign ovarian tumours were studied within 15 years from 2002 to 2016 in Silchar Medical College, Silchar. Out of which 100 each is taken for vaginal, abdominal and laparoscopic panhysterectomy. All patients were elderly above 40 years, parous and without any uterine descent. Results: Hundred successful vaginal panhysterectomies were carried out. Seventy five $(75 \%)$ of the ovarian tumour removed enmass in collapsed state (punctured and fluid drained vaginally). Adenomyosis was the commonest benign condition associated (18\%). Bisection was done in 40 patients and myomectomy in 5 patients. The amount of blood loss during surgery, duration of surgery and length of hospital stay was significantly more in the abdominal hysterectomy in comparison to vaginal hysterectomy. Requirement of blood transfusion was more in abdominal group in comparison to vaginal and laparoscopic group. Conclusion: In this study it was found that the vaginal panhysterectomy can be safely performed in cases of benign ovarian tumours in non descent uterus, though it requires the expertise and experience of the surgeon.
\end{abstract}

Keywords: Non descent vaginal hysterectomy, benign ovarian tumour, morcellation.

Pan-hysterectomy is one of the most commonly performed surgery in parous ladies with benign ovarian tumours ${ }^{1}$. Previously (2000 to 2004) most of the hysterectomies were performed through the abdominal route. It is associated with greater number of complications. Pan-hysterectomy carried out laparoscopically is costly, requires trained personals and facilities. Vaginal hysterectomy is the procedure of choice in parous women unless contraindicated. Post op recovery is faster in laparoscopic and vaginal hysterectomy than compared to abdominal hysterectomy ${ }^{2}$.

A cochrane review of 27 randomised control trials ${ }^{3}$ compared abdominal hysterectomy with vaginal and three types of laparoscopic hysterectomies. The main observation was shorter length of hospital stay, faster post operative recovery, and decreased febrile morbidity of vaginal and laparoscopic hysterectomy

Received: $13^{\text {th }}$ March 2017. Accepted: $3^{\text {rd }}$ May 2017.

Choudhury AP, Nath P. Non descent vaginal pan hysterectomy in benign ovarian tumour in elderly parous patients - an experience. The New Indian Journal of OBGYN. 2017; 4(1):66-70 
compared with abdominal hysterectomy ${ }^{4-6}$. Keeping in concern, the containment of health, as vaginal hysterectomy is associated with fewer complication, faster recovery and also cost effective we have decided to study non descent vaginal hysterectomy in elderly parous women associated with benign ovarian tumour and to analyse the advantages of the procedure over abdominal route and laparoscopically.

\section{Methodology}

Three hundred (300) patients requiring pan hysterectomy for benign ovarian tumours were studied. Out of which 100 each is taken for vaginal, abdominal and laparoscopic pan hysterectomy. Patients were elderly above 40 yrs, parous and without any uterine descent. Prerequisites for vaginal route were : uterine size not more than $16 \mathrm{wks}$, ovarian tumours $>10 \times 10$ cms upto 32 wks size were included, adequate vaginal access including the uterine mobility. Malignancy excluded as per exclusion criteria mentioned below. Exclusion of malignancy was done by 1) Clinical findings correlating to a benign ovarian mass, 2) Serum markers, 3) Colour Doppler, 4) MRI findings, 5) Complex ovarian mass. Informed consents were taken.

All cases of vaginal hysterectomy were done under regional anaesthesia, either spinal or epidural. All cases of laparoscopic hysterectomy were done under general anaesthesia (GA). Abdominal hysterectomies were done both under regional anaesthesia and GA. After proper antiseptic cleaning and draping, cervix was held with volsellum. Circumferential incision was taken around the cervix. Pubo-cervical ligament was dissected and bladder pushed up. Both anterior and posterior pouches opened. Uterosacral ligament and cardinal ligaments identified, clamped, cut and ligated. Following clamping of the uterine vessels, it was also cut and ligated. The ovarian tumour in majority of the cases were removed enmass in collapsed condition( puncture followed by drainage of the ovarian content, where no amount of fluid was allowed to enter the abdominal cavity, assisted by the assistant by giving suprapubic pressure); where as in rest of the cases piecemeal extraction was done. Uterine bisection was performed in cases where uterus was bulky and myomectomy performed in cases associated with fibroid. Vaginal hysterectomy was considered successful if it was not abandoned or converted to abdominal route.

The operating time was noted from time of incision till the end of the procedure. To measure intraoperative blood loss, weight of swab in the dry and blood soaked states was measured and $19 \mathrm{mg}$ weight difference was equated to $1 \mathrm{ml}$ blood loss. The primary outcome measures were operative time, intraoperative blood loss, hospital stay, blood transfusion, wound infection and postoperative systemic infections. Data was statistically analysed using Chi-square test and p-value was determined.

\section{Results}

Hundred (100) successful vaginal panhysterectomies were carried out. Seventy five $(75 \%)$ of the ovarian tumour removed enmass in collapsed state
Table 1: Age, parity, associated gynaecological conditions, morcellation technique, and surgical result of vaginal panhysterectomy group. $(\mathrm{N}=100)$

\begin{tabular}{lll}
\hline Categories & & Number \\
\hline Age in yrs & $40-45$ & 60 \\
& $46-50$ & 30 \\
Parity & $51-55$ & 10 \\
& 2 & 10 \\
Associated different & $\geq 4$ & 28 \\
gynaecological & Adenomyosis & 62 \\
conditions in & Fibroid & 18 \\
ovarian & DUB & 10 \\
tumours & Chronic pelvic pain & 10 \\
Morcellation technicque & Bisection of uterus & 40 \\
& Myomectomy & 5 \\
& Piecemeal & 25 \\
Surgical result & Intact uterus & 30 \\
& Average operating time & $50 \mathrm{mins}$ \\
& Average blood loss & $200 \mathrm{ml}$ \\
& Average hospital stay & 3 days \\
\hline
\end{tabular}


Table 2: Comparison of blood loss, operating time, length of hospital stay

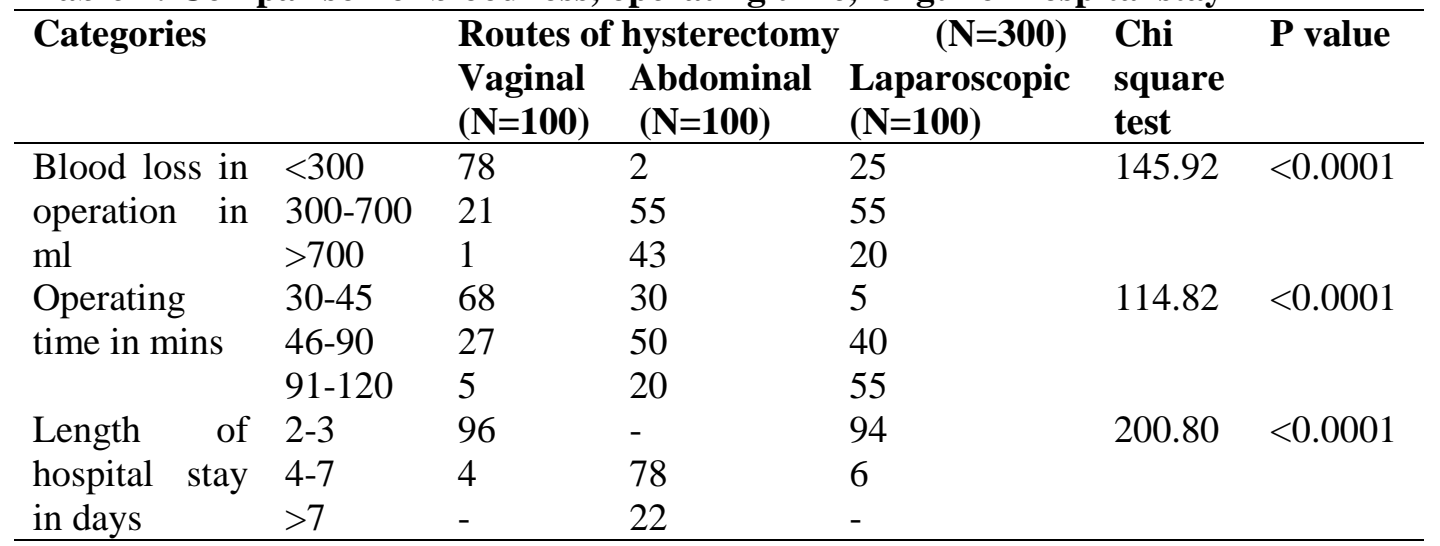

(table 2). The duration of surgery was $30-45$ minutes in maximum cases $(68 \%)$ of vaginal group, whereas, in abdominal and laparoscopic group maximum number of surgery were completed within 46-90 mins and 90- (punctured and fluid drained vaginally). Most of these parous women had a parity of three or more, a favourable point for vaginal hysterectomy. They were in the age group of 40-45 yrs (60\%). Adenomyosis was

Table 3: Complications

\begin{tabular}{llll}
\hline Complications & $\begin{array}{l}\text { Vaginal } \\
\text { hysterectomy }\end{array}$ & $\begin{array}{l}\text { Abdominal } \\
\text { hysterectomy }\end{array}$ & $\begin{array}{l}\text { Laparoscopic } \\
\text { hysterectomy }\end{array}$ \\
\hline UTI & 10 & 16 & 7 \\
RTI & 4 & 9 & 22 \\
Burst abdomen & 0 & 4 & 0 \\
Wound & 8 & 6 & 1 \\
infection & & & \\
Bladder injury & 2 & 1 & 3 \\
Bowel injury & 0 & 2 & 5 \\
Leg pain & 3 & 0 & 4 \\
$\begin{array}{l}\text { Blood } \\
\text { transfusion }\end{array}$ & 2 & 22 & 8 \\
\hline
\end{tabular}

120 mins res- pectively, implying a significant difference $(p<0.0001)$. Similarly, a significantly higher blood loss was noted in the abdominal hysterectomy group, compared to vaginal group and laparoscopic group ( $p<0.0001)$. The length of hospital stay was significantly longer in the abdominal group in comparison to vaginal and laparoscopic group $(\mathrm{p}<0.0001)$ (table 2).

Lesser number of patients required postoperative blood transfusion in the vaginal group $(n=2)$ compared to the laparoscopic group $(\mathrm{n}=8)$ and abdominal group $(n=22)$. But slightly high postoperative wound infection rate was noted $(n=8)$ in vaginal group, compared to the laparoscopic group $(\mathrm{n}=0)$. However, the number of systemic infection like respiratory tract infection was more in laparoscopic group $(n=22)$ in comparison to abdominal

the commonest benign condition associated (18\%). In 68 patients uterus was bulky weighing upto $400 \mathrm{gms}$, remaining 32 patients had uterus less than $200 \mathrm{gms}$. Bisection was done in 40 patients and myomectomy in 5 patients. Operating time was 50 mins on average with blood loss less than $200 \mathrm{ml}$ and hospital stay of 3 days (table 1). None of the cases in the vaginal group were converted to abdominal route.

The vaginal panhysterectomy group was compared with abdominal and laparoscopic hysterectomy group $(n=9)$ and vaginal group $(n=4)$. Similarly bladder and bowel injury was slightly more in laparoscopic group in comparison to other two groups (table 3 ).

\section{Discussion}

Big, bulky uteri in vaginal hysterectomies can be dealt with bisection, piecemeal and myomectomy can be performed in cases associated with uterine fibroid. Davies et al ${ }^{7}$ and Mazdisian et al ${ }^{8}$ also reported to these techniques. In the present study, upto 16 week size uterus was removed vaginally without any increase 
in surgical complications. Similar findings were reported by Unger ${ }^{9}$ who operated upon uteri weighing upto $700 \mathrm{gms}$ without any increase in complications.

In the non descend vaginal hysterectomy (NDVH) group, operating time in majority patient $(\mathrm{n}=95)$ was between 30-90 minutes and the remaining 5 patients it was 90-120 minutes which was comparable to the studies by Mehla $S$ et al ${ }^{10}$ and Shahana et al ${ }^{11}$ The duration of surgery in maximum cases of total abdominal hysterectomy (TAH) ranged between $46-$ 90 minutes which was comparable to Mahasani $\mathrm{V}^{12}$ et al (TAH 1 hour 20 minutes and NDVH 45 minutes). In the study by Patel et al ${ }^{13}$ in laparoscopic hysterectomy took almost double the time as NDVH. This finding was comparable to present study.

Average blood loss in NDVH group was $200 \mathrm{ml}$ which was comparable to the studies by Mehla $\mathrm{S}$ et $\mathrm{al}^{10}$ $(205 \mathrm{ml})$ and Shahana et $\mathrm{al}^{11}(200 \mathrm{ml})$. In the study by Mahasani $\mathrm{V}$ et al ${ }^{12}$, TAH had the fourth time blood loss in comparison to NDVH. In the present study also maximum amount of blood loss observed in abdominal group (55\% cases had blood loss 300-700ml, 43\% cases had blood loss $>700 \mathrm{ml}$ ).

In the vaginal hysterectomy group $96 \%$ and laparoscopic group 94\% were discharged within 3days. In vaginal and laparoscopic group no patient was hospitalized more than 7 days which was comparable to Mehla $\mathrm{S}$ et al ${ }^{10}$ (5 days), Dewan $\mathrm{R}$ et $\mathrm{al}^{14}$ (3 days). Maximum number of patient in abdominal group $(n=78)$ were hospitalized for $4-7$ days which was comparable to the studies by Sutasanasuang $\mathrm{S}$ et $\mathrm{al}^{15}$ (TAH 5.3 \pm 4.3 days and TLH 3.2 \pm 1.1 days) and Singh A et $\mathrm{al}^{16}$ (NDVH 3.71 days and TAH 7.84 days).

Intraoperative complication like bladder and bowel injury occurred in 13 patients, with 8 patients in laparoscopic group, followed by 3 patients in abdominal group and 2 patients in the vaginal group which was comparable to the study by Gilmour DT et al ${ }^{17}$. Most common post operative complications in this study was urinary tract infection which complicated 16 cases of abdominal group, 10 cases of vaginal group and 7 cases of laparoscopic group. Second most common postoperative complication was respiratory tract infection which complicated 22 cases in laparoscopic group but only four cases of vaginal group. In this study, 32 no of patients required blood transfusion which comprised of 22 no patients in abdominal group, 8 no patients in laparoscopic group and 2 no of patients in vaginal group. These results were comparable to the studies by Mehla $\mathrm{S}$ et $\mathrm{al}^{10}$ and Mahasani $\mathrm{V}$ et al ${ }^{12}$.

\section{Conclusion}

It is a very well known fact that majority of vaginal hysterectomies are mainly performed in cases associated with prolapse. But with adequate vaginal assess and good surgical and technical skills vaginal hysterectomy can be easily performed in non-descent cases. Multiparity, lax tissues due to poor involution following multiple deliveries provide a good comfort to surgeons in performing the vaginal hysterectomies. In the 100 cases of benign ovarian tumours included in this study in non descent uterus, vaginal pan hysterectomy was easily performed provided the assistant provides a good tamponade so that while aspiration no fluid or cyst content is allowed to enter the abdominal cavity whereas there is associated risk of spillage of contents in both abdominal and laparoscopic hysterectomies. On addition abdominal hysterectomy is associated with the drawback of more blood loss, longer operating time and hospital stay. As we know this is an era of laparoscopy and patient preferably want to undergo minimally invasive procedures, if cost is considered, vaginal hysterectomy is the best option in such cases that can be offered by an experienced surgeon to the patients.

\section{Acknowledgement}

We gratefully acknowledge the help of Dr. Baisya, MD, Superintendent, Silchar Medical College and Hospital, Silchar; Dr. Asmita, Dr. Menon, Dr. Meghnath, Dr. Jatin, Dr. Kshitija, Dr. Chaitra, Dr. Sujoy and Dr. Smita.

Conflict of interest: None. Disclaimer: Nil. 


\section{References}

1.Wu JM, Wechter ME, Geller EJ, Nguyen TV, Visco AG. Hysterectomy Rates in the United States, 2003. Obstet Gynecol. 2007;110:1091-5

2.Garry R, Fountain J, Mason S. The evaluate study: two parallel randomised trials one comparing laparoscopic with abdominal hysterectomy, the other comparing laparoscopic with abdominal hysterectomy, the other comparing laparoscopic with vaginal hysterectomy. BMJ. 2004;328:129-36.

3.Berek JS. Berek and Novak's Gynaecology. 15 th edition. New York: Lippincott Williams \& Wilkins; 2012.

4.Falcone TMD, Paraiso MFR, Mascha EMS. Prospective randomized trial of laparoscopically assisted vaginal hysterectomy versus total abdominal hysterectomy. Am J Obstet Gynecol 1999;180: 955-62.

5.Phipps JH, Nayak JS. Comparison of laparoscopic assisted vaginal hysterectomy and bilateral salpingooophorectomy with conventional abdominal hysterectomy and bilateral salpingo-oophorectomy. Br J Obstet Gynaecol 1993;100: 698-700.

6.Soriano S, Goldstein A, Lecuru F, Darai E. Recovery from vaginal hysterectomy compared with laparoscopyassisted vaginal hysterectomy. Acta Obstet Gynaecol 2001;80: 337-41.

7.Davies A, Wizza E, Bournas $\mathrm{N}$ et al. how to increase the proportion of hysterectomies performed vaginally. Am J Obstet Gynecol 1998;179:1008-12.

8.Mazdisnian F, Kuzrel RB, Coe S et al. Vaginal hysterectomy by uterine morcellation : efficient, nonmorbid procedure. Obstet Gynecol 1995; 86:60-4.

9.Unger JB. Vaginal hysterectomy for the women with moderately enlarged uterus weighing 200 to 700 grams. Am J Obstet Gynecol 1999;180:1337-44.
10.Mehla S, Chutani N, Gupta M. Non descend vaginal hysterectomy: personal experience of 105 cases. Int J Reprod Contracept Obstet Gynecol. 2015; 4(1): 61-5.

11.Begum S, Akhtar R, Barua S, Ferdous J. A cross sectional descriptive study on non descend vaginal hysterectomy. Chattagram Maa - O -Shishu Hospital Medical College Journal. 2014; 13(1):13.

12.Mahasani V, Suchdeva R, Aggrawal A. Hysterectomy which approach? People's Journal of Scientific Research. 2014; 7(1): 17-21.

13.Patel R, Chakravarty N. Comparative study of laparoscopic hysterectomy versus vaginal hysterectomy. Int J Med Sci Public Health. 2014; 3(3):335-7.

14.Dewan R, Agarwal S, Minocha B, Sen SK. Non descend vaginal hysterectomy: an experience. J Obstet Genecol India. 2004; 54(4): 376-8.

15.Sutasanasuang S. Laparoscopic hysterectomy versus total abdominal hysterectomy: a retrospective comparative study. J Med Assoc Thai. 2011; 94(1): 8-16.

16.Singh A, Bansal S. Comparative study of morbidity and mortality associated with non descend vaginal hysterectomy based on ultrasographic determination of uterine volume. Int Surg. 2008; 93(2): 88-94.

17.Gilmour DT, Das S, Flowerdew G. Rates of urinary tract injury from gynecologic surgery and the role of intraoperative cystoscopy.Obstet Gynecol. 2006;107:1366-72.

\section{Arun Paul Choudhury ${ }^{1}$, Pranoy Nath ${ }^{2}$}

${ }^{1}$ Associate Professor, Department of Obstetrics and Gynaecology, Silchar Medical College, Silchar, Assam, India; ${ }^{2}$ Associate Professor, Department of Obstetrics and Gynaecology, Silchar Medical College, Silchar, Assam, India. 